\section{Reduced Caloric Intake and Nicotinic Acid Provocation Tests in the Diagnosis of Gilbert's Syndrome}

Gilbert's syndrome is a benign condition characterized by a mild unconjugated hyperbilirubinaemia without severe haemolysis or liver disease. Fluctuations in the blood bilirubin levels can make the diagnosis difficult. We have compared the results of two tests-the fasting or reduced caloric intake test, and the nicotinic acid provocation test-which have recently been advocated for diagnosing Gilbert's syndrome. ${ }^{12}$

\section{Patients, Methods, and Results}

All 16 male patients with Gilbert's syndrome had otherwise normal liver function tests, reticulocyte count, and histological otherwise normal liver function tests, reticulocyte count, and histological appearances of a needle
liver biopsy specimen. For the fasting or rediced caloric intake test the liver biopsy specimen. For the fasting or rediced caloric intake test the
patients were admitted to hospital and after one to three days were given patients were admitted to hospital and after one to three days were given
a $1.67 \mathrm{MJ}$ ( 400 calorie) diet for 48 hours. The nicotinic acid test was carried a $1.67 \mathrm{MJ}$ ( 400 calorie) diet for 48 hours. The nicotinic acid test was carried
out, usually in outpatients, after an overnight fast. Fifty mg nicotinic acid
was given by slow intravenous injection over 30 seconds and blood samples was. given by slow intravenous injection over 30 seconds and blood samples
for the estimation of plasma bilirubin were withdrawn at 30 -minute intervals for the estimation of plasma bilirubin were withdrawn at 30-minute intervals experienced mild flushing, and several noted a transient metallic taste. Plasma total and unconjugated bilirubin levels were estimated using Michaelsson's method (normal values less than $17 \mu \mathrm{mol} / \mathrm{l}$ ). The reduced caloric intake test was carried out in 13 patients with Gilbert's syndrome. The mean plasma total and indirect-reacting bilirubin levels rose during the $48 \mathrm{~h}$ period, but this rise failed to reach statistical significance: mean ( \pm 1 S.D.) plasma bilirubin $30.1 \pm 15.4 \mu \mathrm{mol} / 1$ before and $35.2 \pm 17.8 \mu \mathrm{mol} / 1$ at the end $(t=2.06 ; 0.05>\mathrm{P}<0.1)$. Four patients showed a rise of over double but in the others the rise was less; indeed, in one patient the bilirubin level fell in the others the rise was less; indeed, in one patient the bilirubin level fell
from 49.6 to $44.5 \mu \mathrm{mol} / 1$. In only one patient was the initial bilirubin level from 49.6 to $44.5 \mu \mathrm{mol} / 1$. In only one patient was the initial bilirubi
within the normal range, and the rise in this patient was less than half.

within the normal range, and the rise in this patient was less than half. six control subjects had risen within 30 minutes after the injection, with plateau from 90 minutes and falling after 180 minutes. This rise was due to an increase in the indirect-reacting, and therefore probably unconjugated, fraction. In 16 patients with Gilbert's syndrome there was a similar rise in bilirubin, but the increase was greater, and peak values occurred later at 180 minutes when there was a definite difference between control subjects and the patients. The mean increase in plasma bilirubin at 180 minutes compared with initial levels was significantly higher in the patients $(23.3 \pm 8.9 \mu \mathrm{mol} / 1)$ than in the controls $(6.5 \pm 4.8 \mu \mathrm{mol} / 1)(P<0.001)$ (see fig.). In two patients initial bilirubin levels were normal, and rose by 20.5 and $17 \cdot 1 \mu \mathrm{mol} / 1$ after nicotinic acid.

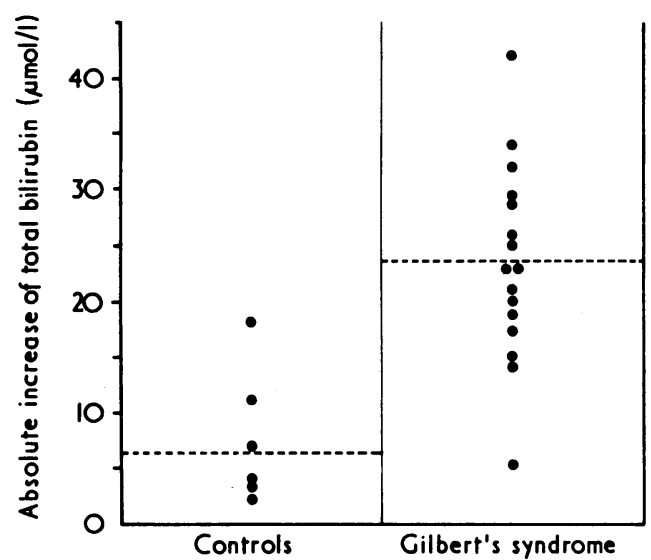

The increase in plasma total bilirubin level 180 minutes after the administration of nicotinic acid in contro subjects and patients with Gilbert's syndrome. Mean values are shown by dotted lines.

\section{Discussion}

We found that the reduced caloric intake test was less reliable than reported..$^{3-5}$ An increase of $100 \%$ occurred in only four of our patients tested, and this uncertainty is likely to be greater when routine bilirubin estimations are done. Admission to hospital is also necessary. The diagnosis of those patients whose initial bilirubin levels are normal is difficult; our patient, and two of Owens and Sherlock ${ }^{2}$ in this condition, showed only small rises.

The effect of nicotinic acid injection on bilirubin levels was first described by Mattei, ${ }^{5}$ and it has been studied in patients with Gilbert's syndrome. ${ }^{2}$ The mechanism is unknown. We found the nicotinic acid provocation test more reliable in distinguishing between patients with Gilbert's syndrome and normal subjects. Only one measurement at 180 minutes after the administration of nicotinic acid is needed, and this test is also easier to perform on outpatients than is the reduced caloric intake test, while a positive response was found even in the two patients with normal plasma bilirubin levels. It could therefore prove valuable as an additional investigation in patients with suspected Gilbert's syndrome and especially in those in whom the bilirubin level has fallen to normal.

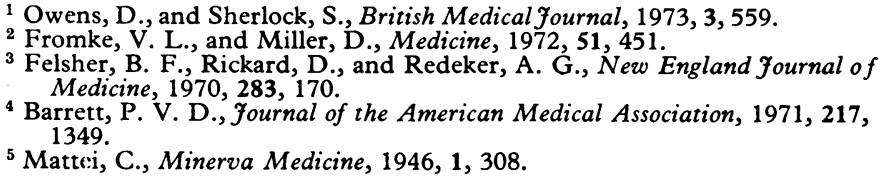

The Liver Unit, King's College Hospital and Medical School, London

A. R. DAVIDSON, M.R.C.P., M.R.C.S., Research Fellow

A. ROJAS-BUENO, M.D., Research Fellow

R. P. H. THOMPSON, D.M., M.R.C.P., Honorary Senior Lecturer ROGER WILLIAMS, M.D., F.R.C.P., Consultant Physician, and Director of the Liver Unit

\section{Co-trimoxazole in Chronic Brucellosis: A Two-year Follow-up Study}

The relatively recent introduction of co-trimoxazole for acute brucellosis ${ }^{1-8}$ has given good results and low relapse rates. ${ }^{4}$ There is limited information on the drug's efficacy in the chronic disease-the most difficult therapeutic problem. ${ }^{5}$ We report a two-year follow-up of 20 treated patients with chronic brucellosis.

\section{Patients, Methods, and Results}

During 1971 and 197220 patients who fulfilled the following criteria were studied: (a) admission to hospital for brucellosis elsewhere six to 12 months before admission; $(b)$ isolation of Brucella mellitensis in blood or bone marrow cultures; $(c)$ treatment with broad-spectrum antibiotics commonly used in cultures; $(c)$ treatment with broad-spectrum antibiotics commonly used in acute brucellosis. Their main symptoms were arthralgia, general malaise, weight loss, backache, and low grade fever. Alternative diagnoses were evidence of localized disease. Brucella was not isolated in either the blood or bone marrow cultures. They were given co-trimoxazole (Septrin); three tablets twice daily until they became afebrile and then two tablets twice daily for a total of two months. Investigations were performed regularly for possible side effects on the bone marrow and on liver and renal function. After two months of treatment and for two years all patients completed a detailed questionnaire on any possible complaints attributable to the disease or to the drug.

Fever subsided in all within two to seven days, though disappearance of other symptoms was delayed (table). Every patient's general condition was improved on discharge. Serum agglutination titres fell significantly in 11 patients and became negative in seven patients after two years. Two patients patients and became negative in seven patients after two years. Two patients relapsed one month after the end of treatment. They were given a further No serious side effects required discontinuation of treatment. Three patients developed a transient rash which subsided quickly with the use of antideveloped a
histamines.

\section{Discussion}

The main difficulties in the treatment of brucellosis are to prevent relapses and to cure the disease totally. The appearance of relapses three months after the onset of the disease suggests chronicity. It is not always easy to distinguish between relapses and true reinfections, since patients return to their infected areas. We selected our patients to exclude that possibility. They were all confirmed cases of brucellosis who had been treated with broad-spectrum antibiotics and had been advised to avoid all possible sources of infection. None of them had the typical clinical picture of the acute onset of the disease. Two patients relapsed quickly after the cessation of treatment suggesting 
Treatment of Chronic Brucellosis with Trimethoprim-sulphamethoxazole

\begin{tabular}{|c|c|c|c|c|c|c|c|}
\hline $\begin{array}{l}\text { Case } \\
\text { Ṇo. }\end{array}$ & Sex & $\begin{array}{c}\text { Age } \\
\text { (Years) }\end{array}$ & $\begin{array}{c}\text { Blood and Bone } \\
\text { Marrow Cultures }\end{array}$ & $\begin{array}{c}\text { Serum Agglutination } \\
\text { Titre }\end{array}$ & $\begin{array}{c}\text { No. of Days to Become } \\
\text { Afebrile }\end{array}$ & Relapses & $\begin{array}{c}\text { Serum Agglutination } \\
\text { Titre After } 2 \text { Years }\end{array}$ \\
\hline $\begin{array}{r}1 \\
2 \\
3 \\
4 \\
5 \\
6 \\
7 \\
8 \\
9 \\
10 \\
11 \\
12 \\
13 \\
14 \\
15 \\
16 \\
17 \\
18 \\
19 \\
20\end{array}$ & $\begin{array}{l}\text { F. } \\
\text { F. } \\
\text { M. } \\
\text { M. } \\
\text { M. } \\
\text { M. } \\
\text { M. } \\
\text { M. } \\
\text { F. } \\
\text { F. } \\
\text { M. } \\
\text { M. } \\
\text { M. } \\
\text { M. } \\
\text { F. } \\
\text { M. } \\
\text { M. }\end{array}$ & $\begin{array}{l}60 \\
48 \\
53 \\
20 \\
53 \\
67 \\
46 \\
31 \\
30 \\
55 \\
23 \\
50 \\
58 \\
17 \\
60 \\
45 \\
26 \\
45 \\
59 \\
45\end{array}$ & 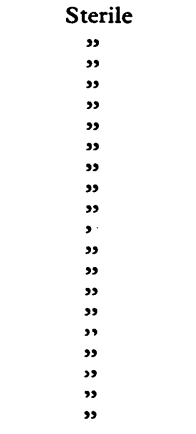 & $\begin{array}{r:r}1 & : 1280 \\
1 & 640 \\
1 & 1280 \\
1 & 1280 \\
1 & 640 \\
1 & 1280 \\
1 & 1280 \\
1 & 1280 \\
1 & 12840 \\
1 & 1280 \\
1 & 1280 \\
1 & : 1280 \\
1 & 1280 \\
1 & 640 \\
1 & 1280 \\
1 & 1280 \\
1 & 1280 \\
1 & 1280 \\
1 & 640 \\
1 & : 1280\end{array}$ & $\begin{array}{l}3 \\
4 \\
4 \\
2 \frac{1}{2} \\
4 \\
2 \\
5 \\
4 \\
3 \\
3 \\
3 \\
4 \\
3 \\
3 \\
7 \\
4 \\
4 \\
3 \frac{1}{2} \\
2 \\
3 \frac{1}{2}\end{array}$ & $\begin{array}{l}\text { No } \\
\text { No } \\
\text { No } \\
\text { No } \\
\text { No } \\
\text { No } \\
\text { No } \\
\text { No } \\
\text { No } \\
\text { No } \\
\text { Yes } \\
\text { No } \\
\text { No } \\
\text { No } \\
\text { No } \\
\text { No } \\
\text { Yes } \\
\text { No } \\
\text { No } \\
\text { No }\end{array}$ & 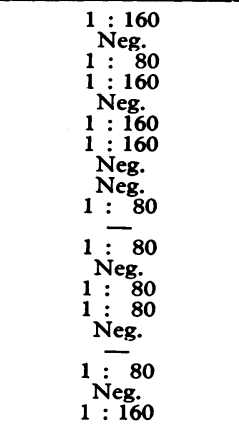 \\
\hline
\end{tabular}

either inadequate treatment or reinfection. The rest had no trouble during the two-year follow-up and were apparently cured. We believe, despite the two failures, that co-trimoxazole can be used effectively in the treatment of chronic brucellosis and that our dosage schedule is adequate, though more information is needed about the long-term results.

1 Hassan, A., et al., British Medical fournal, 1971, 3, 159.

2 Lal, S., et al., British Medical fournal, 1970, 3, 256.

3 Giunchi, G., De Rosa, F., and Fabiani, F., Chemotherapy, 1971, 16, 332.

4 Daikos, G. K., et al., fournal of Infectious Diseases, 1973, 128 Supp., 731.

5 British Medical fournal, 1974, 1, 299.

State Hospital for Infectious Diseases, Athens, Greece

P. A. KONTOYANNIS, M.D., Head Medical Department

S. E. PAPAPOULOS, M.D., Senior House Officer

A. A. MORTOGLOU, M.D., Senior House Officer in Medicine

\section{Orbital Bruits in Patients on Maintenance Haemodialysis}

Cranial or onbital bruits, or both, are typically heard in patients with cranial arteriovenous fistula and angioma. In children cranial bruits may be heard as a result of transmission of cardiac murmur to the cranium. Other conditions with cranial bruits include carotid artery stenosis and intrathoracic aneurysm, aneurysm of the posterior fossa, Paget's disease of the skull, aortic stenosis, and arterial hypertension in young children. Cranial bruit was first noted in an anaemic woman 44 years $\mathrm{ago}^{1}$ and several cases were described recently. ${ }^{2}$ As most patients with renal failure on maintenance dialysis have severe anaemia, it was reasoned that these patients may also have cranial bruit and a study was made.

\section{Case History}

Twenty-two patients on maintenance haemodialysis were studied at the University of Illinois Hospital. The diaphragm of the stethoscope was placed lightly on the orbit with the patient's eyes closed. Auscultation was done while the patient held his breath, before, during, and after dialysis and after occlusion of arteriovenous fistula. The bruits were graded as follows: grade $0=$ bruit absent, grade $1=$ bruit just audible, grade $2=$ bruit easily audible, and grade $3=$ loud bruit. The blood pressure, pulse rate, presence of cardiac murmurs, carotid bruits, haematocrit value, and weight before and after dialysis were recorded. Statistical analysis was computed by the paired $t$ test. Orbital bruits were absent in five patients, grade 1 in five, grade 2 in seven, and grade 3 in five. After occlusion of the arteriovenous fistula the bruit was absent in eight patients, grade 1 in six, grade 2 in six, and grade 3 in two. There was no change in the intensity of the bruit before, during, or after dialysis. The mean haematocrit value was $20 \%$ (range 12.4-30.5\%). The patients with orbital bruits had a lower haematocrit value than those without $(P<0.2)$, but there was no direct correlation between its level and the intensity of the bruit. The average blood pressure was $135 / 85 \mathrm{~mm}$. (range 70/50-160/10). The mean pulse rate was 89/min (range 76-120). The (range $70 / 50-160 / 10)$. The mean pulse rate was $89 / \mathrm{min}$ (range $76-120$ ). The heard in 16 patients and carotid bruits in six. None of these factors had any effect on the presence or intensity of the bruits.

\section{Discussion}

Examination of the head for cranial and orbital bruit is not routinely done though the many conditions that may produce them highlight the importance of this examination, particularly in pat:ents with neurological and cardiac abnormalities. Severe anaemia increases cardiac output, which leads to an inoreased cerebral blood flow. ${ }^{4}$ There is also generalized vasodilatation and decrease in blood viscosity. Under these circumstances cranial bruits are thought to result from turbulent blood flow in the cerebral arteries. Patients on maintenance haemodialysis have severe anaemia and, not surprisingly, orbital bruits are usual in these patients. The bruit appears to be intensified by an anteriovenous fistula; this is supported by the disappearance of some bruits and reduction in intensity of others with occlusion of the fistula. The fistula may contribute to $12 \%$ increase in cardiac output $^{5}$ and this may be higher with large fistula. Some patients develop heart failure because of the high output state. Patients on maintenance haemodialysis may develop various neurological abnormalities such as convulsions, stroke, and subdural haematoma. Nevertheless, the presence of a cranial bruit should not be readily attributed to an intracranial lesion. Recognition of anaemia as the cause of the bruit should make extensive examination unnecessary unless other neurological disorders are present.

${ }^{1}$ Hamburger, L. P., American fournal of the Medical Sciences, 1931, 181 756.

-Gareebo, H., British Medical fournal, 1968, 1, 294.

3 Gardner-Thorpe, C., British Medical fournal, 1968, 1, 445.

${ }^{4}$ Heyman, A., Patterson, J. L., and Duke, T. W., Journal of Clinical Investigation, 1952, 31, 824

${ }^{5}$ Charra, B., et al., Kidney International, 1973, 3, 51.

\section{V.A. West Side Hospital and University of Illinois; Abraham Lincoln} School of Medicine, Chicago, Illinois

S. R. LANCER, B.S., Final year medical student

V. K. G. PILLAY, M.R.C.P., Chief, Section of Nephrology 